\title{
Neuropsychological and Behavioral Aspects of Noonan Syndrome
}

\author{
Ellen Wingbermühle ${ }^{a}$ Jos Egger ${ }^{a, b}$ Ineke van der Burgt ${ }^{c} \quad$ Willem Verhoeven $^{a, d}$ \\ ${ }^{a}$ Centre of Excellence for Neuropsychiatry, Vincent van Gogh Institute for Psychiatry, Venray, \\ ${ }^{\mathrm{b}}$ Behavioural Science Institute, Radboud University, and 'Department of Human Genetics, Radboud University \\ Medical Centre, Nijmegen, and ${ }^{\mathrm{d}}$ Department of Psychiatry, Erasmus University Medical Centre, Rotterdam, \\ The Netherlands
}

\section{Key Words}

Noonan syndrome $\cdot$ Neuropsychology $\cdot$ Social cognition •

Alexithymia $\cdot$ Quality of life

\begin{abstract}
The current paper introduces concise neuropsychological assessment as an essential tool for studying the contribution of cognition and behavior in the expression of genetic syndromes, like Noonan syndrome (NS). Cognitive and behavioral findings in NS show intelligence scores across a wide range, with a mildly lowered average level. Language and motor development are often delayed, but no longer dysfunctional in adulthood. Continuing mild problems in selective and sustained attention are noted, as well as suboptimal organization skills and compromised abilities to structure complex information. These problems seem to culminate in learning difficulties, requiring attention for special needs in education. It seems that a complex of psychosocial immaturity, alexithymia and amenable traits is typical of NS patients. Consequently, psychopathology or psychological problems in leading a self-serving life may often remain underreported. This is why the authors advocate the integration of the domain of social cognition and personality in NS assessment.

Copyright $\odot 2009$ S. Karger AG, Basel
\end{abstract}

\section{Neuropsychological Framework in Genetic Research}

While neuropsychology shares a main principle with neurology in considering brain function as a frame of reference, the subject matter is always behavior. It is the research discipline that combines neurosciences with social sciences and focuses on relations between brain and human cognitive, emotional and behavioral functions. In this respect, cognition can be defined as the informationhandling aspect of behavior [1].

Because of its interdisciplinary identity, neuropsychology can provide a suitable framework for theorizing on relations between genetic, neural or somatic makeup on the one hand, and cognitive and behavioral manifestations on the other. Knowledge about the interplay between these levels of functioning is important for our theoretic understanding of Noonan syndrome (NS), for diagnosing pathological manifestations on either of the levels mentioned, as well as for identifying clinical treatment needs. The neuropsychological approach can contribute to the decomposition of symptoms and behavioral presentations of genetic disorders, and because of this focus on the cognitive level, it is very appropriate in the identification of candidate endophenotypes [2].

\section{KARGER}

Fax +4161306 1234

E-Mail karger@karger.ch

www.karger.com (c) 2009 S. Karger AG, Basel

0301-0163/09/0728-0015\$26.00/0

Accessible online at:

www.karger.com/hre
Ellen Wingbermühle

Centre of Excellence for Neuropsychiatry, Vincent van Gogh Institute for Psychiatry Stationsweg 46

NL-5803 AC Venray (The Netherlands)

Tel. +31 478527 339, Fax +31 478527 626, E-Mail pwingbermuhle@ggznml.nl 
Only limited data are available on the (neuro)psychology of NS, leaving many questions unanswered. Still, when reviewing the existing research, some remarkable patterns in information processing and behavior emerge, which deserve the attention of caregivers, teachers, doctors and psychologists who work with children or adults with NS. To facilitate understanding and appraisal of the NS-specific findings, some brief background information on measuring and interpreting behavior will be presented first.

\section{Measuring Cognition and Behavior}

In neuropsychology, interactions between brain and behavior are analyzed by systematically evaluating cognitive function domains. These function domains are described by theoretical constructs, reflecting the multiple aspects of mental processes involved in thinking and experiencing. Traditionally, the following domains are distinguished: intelligence, learning and memory, attention and information speed, executive functions, verbal functions, perception and motor functions/praxis [1]. These 'cold' cognitive functions dominated theory and research in the neurosciences for a long time. Recently, 'hot cognition', i.e. the cognitive processes involved in social interaction, including affective or emotional experiences, have received growing attention. It should be stressed that the segmentation of the cognitive domains is only conceptual. In fact, the distinct functions are mutually dependent and operate in close harmony.

A psychologist makes use of several methods and techniques when performing a neuropsychological assessment. Such an assessment typically comprises structured interviews, informal and formal (test-based) observations, and a wide array of tests. Every serious neuropsychological assessment should comprise reliable and valid measures of intellectual and other cognitive domains, but also inventories and questionnaires to record psychopathology, personality and quality of life, alongside some specific scales depending on the question under examination (such as rating scales for specific complaints and coping styles). Only employing the method of pattern analysis, i.e. focusing on consistencies and discrepancies within and between various tests and other diagnostic sources, can result in a valid profile of strengths and weaknesses that supports clinical decision-making. Regarding test interpretation, it is important to realize that cognitive impairments can be the result of a wide range of medical and psychological conditions, and that low tests scores may also occur in healthy people [1].

\section{Neuropsychological Profile in NS Children}

When exploring sources of potentially disturbed cognitive abilities in NS, reviewing abnormalities of the CNS that coincide with the syndrome is an obvious first step. The structural brain abnormalities that have been described most often in patients with NS are macrocephaly, hydrocephaly, epilepsy and hemangioma, suggesting vascular changes or malformations to be a key problem [38]. A typical abnormality in this respect is the ArnoldChiari I malformation, a structural defect of the cerebellum associated with balance and other motor functions, and possible cognitive problems as well $[9,10]$. In 2 patients, moyamoya vascular changes have been described [11].

Aside from a handful of reports about more or less infrequent neural complications, systematic research on the structure of the 'normal' NS brain is lacking. As deduction from the physical to cognition does not yet appear to be very fruitful, a bottom-up approach in exploring the neuropsychological makeup of NS seems expedient.

Neuropsychological findings in NS will be presented per cognitive domain, followed by an overview of the literature on psychopathology and personality, including the study of quality of life. The findings in people with NS based on any of the known genetic mutations (PTPN11, $K R A S, S O S 1, R A F 1$ ) will be presented in a mixed form, as a result of the absence of distinctive information.

\section{Intelligence}

Intelligence is not a unitary concept. The intelligence quotient (IQ) refers to a composite score, established by summing the results of a variety of subtests, each associated with different mental abilities. Nevertheless, the total IQ score has proven to be a strong predictor of school performance, and can be considered a measure of general intellectual ability.

Traditionally, verbal intellectual capacities are distinguished from performance capacities. Discrepancies between the verbal and performance levels are too often without question accepted as indicative of some sort of cognitive or psychological syndrome (e.g. nonverbal learning disorder). Nowadays, battery tests discriminating crystallized intelligence (academic skills) and fluid intelligence (problem-solving abilities) are applied by neuropsychologists more and more, as they can offer more relevant information about cognitive functioning.

Intellectual development and intelligence appears to be the best-studied cognitive domain in NS. Almost every non-medical study includes some measure indicating 
the level of intelligence, or at least the level of education, of the subjects under study. Since the 1970s, studies regarding intelligence in NS have shown a broad range of IQ scores, with the level varying from mentally retarded to superior [12-20].

Because of this wide range of individual IQ scores, mean group values are not extremely informative. As reported by several authors, in about one third of NS patients mild mental retardation is found. In general, however, the level of intelligence falls within the normal range [21], with verbal and performance capacities more or less equally divided. Nonetheless, there are indications that up to $50 \%$ of NS patients have special educational needs, underlining the importance of the further analysis of specific cognitive and other adaptive abilities [22].

\section{Language}

With respect to language functions, comprehension of spoken or written language can be divided from expression (speech and writing).

Language skills in children with NS tend to develop slower, which often becomes manifest in problems in articulation (75\%). Both the increased occurrence of hearing loss (15-40\%), due to recurrent otitis media, and the frequently present feeding problems have been suggested to influence language development in a negative manner. Shaw et al. [22] consider feeding problems as an early marker of not only delayed language development, but also long-term educational achievement. A few case-reports have been written about NS children with specific spelling and reading impairments [23-25], and, in the larger cohort of Wood et al. [26], 43\% of the children showed a language impairment. In adulthood, when language is sufficiently learned, problems in this area seem to resolve.

\section{Perceptual and Motor Functions}

Ophthalmic abnormalities can be part of the NS pattern. Nonetheless, functional problems in visual perception (e.g. neglect or agnosia, or even broader problems such as spatial perception) have not been reported as being characteristic of NS.

Motor function or praxis as a cognitive domain focuses on the processes needed to plan and sequentially perform actions, rather than examining the actions themselves. Fine and gross (sensori)motor functions can be divided. The level of visual-motor integration, often measured by hand-eye coordination tasks, is associated with the level of cognitive integration and maturation, and can moderate educational outcome [27].

Neuropsychological and Behavioral Aspects of NS
Mild motor delay and clumsiness have repeatedly been demonstrated in NS. Mostly, they are associated with musculoskeletal changes like hyperextensibility and hypotonia, but a correlation with abnormalities of the cerebellum has also been suggested [24]. The few studies addressing the cognitive components of motor functioning indeed revealed below average achievement on motor coordination tasks, and a developmental coordination disorder has been suggested in half of the children [20,24, 28]. When studying the results in more detail, impaired motor responses (the handling aspects per se) seem to be more explanatory than dysfunctions in visual perception or planning. With increased age and practice, motor skills usually improve.

\section{Memory}

Memory is a very complex concept, comprising many different aspects, which have been discussed by others in great detail [29]. In short, learning demands the encoding, storage, consolidation, and, finally, retrieval of information. Information can be episodic or semantic in nature, and storage can occur explicitly or implicitly. When information is only needed to be kept active for a very short period of time (e.g. remembering a phone number until it is dialed), the memory system involved is referred to as working memory. It is often measured by digit-span tasks. Obviously, working memory and concentration, an aspect of attention, are very closely related concepts.

Learning disabilities are frequently mentioned when discussing the educational careers of NS patients, but memory impairments do not seem to play a key role here. Research focusing on aspects of memory in NS children is very scarce, and the few publications available are based on results of only 1 or 2 tests. Nevertheless, the findings are consistent, pointing out slight problems in working memory and memorizing, but not in storage and retrieval functions per se $[19,24,28]$. Attention problems have been put forward as the underlying cause.

\section{Attention}

The following aspects of attention can be distinguished: concentration and vigilance/sustained attention (staying focused for a shorter or longer period of time), selective attention (resisting interfering stimuli) and divided attention (paying attention to more tasks simultaneously). There are tests and tasks for each of these functions.

Several authors have suggested that attention problems can be regarded as a key dysfunction in NS, having reached this conclusion mainly on the basis of parental evaluations $[19,24,26,30]$. Inattention, in NS literature 
mostly described as a lack of selective or sustained attention, is mentioned frequently, while divided attention is generally thought to be intact. Although it should be noted that many of these findings are not significant when compared to controls, the recurrent observation of inattention is at least conspicuous. Some researchers have even suggested that features of NS children resemble the patterns in $\mathrm{ADD} / \mathrm{ADHD}$ or DAMP (deficits in attention, motor control and perception; a subgroup of ADHD in which a disorder in motor coordination has to be concomitant) $[20,28]$. Aside from the conceptual questions that can be raised with regard to these conditions, there is a lack of systematic, direct (patient-bound) research to substantiate these 'diagnoses'.

\section{Executive Functions}

Executive functioning is an umbrella term for cognitive processes involved in planning, organizing, monitoring and flexibly controlling goal-oriented behavior. It is utilized for problem-solving in new situations, and it is important for successful adaptation to the social environment. The development of the executive functions to their full capacity takes up the entire period of youth, and proceeds even in adolescence and early adulthood. Different aspects evolve at different ages; at the age of about 4 years, basic theory of mind and self-control skills have been established. Because of its complexity and interdependency with other cognitive functions, it is important to employ multiple tests to measure executive functioning.

Executive functioning has not yet been very well studied in NS, which may partly result from fact that this set of cognitive functions did not receive much attention until about a decade ago. Van der Burgt et al. [19] were the first to recognize organizational and planning weaknesses in NS children, emphasizing their causal effect on poor academic task performance and difficulties in school.

\section{Social Cognition and Alexithymia}

Social cognition encompasses the processing of information necessary to adapt to our social environment [31]. It incorporates perception of, attention to, memory for, and thinking about other people in a way that involves emotional and/or motivational processing [32].

Social cognition can for instance be measured by tasks for emotion recognition (processing faces or voices), theory of mind tasks (making inferences about intentions or interpreting social meaning) and tasks in which planning in a social context is required. Another operationalization can be found in the construct of alexithymia.
Studies on the evolution and development of social cognition suggest that this domain can be dissociated from general cognition, as there are specific neural substrates involved that subserve different functions during different stages of development. At the genetic level, there is evidence that specific sets of genes contribute to the development of aspects of social cognition within a particular time course, as found in genetic diseases such as William's syndrome [33].

A shared observation concerns impairments in social competence in NS. Immaturity, a lack of interaction with peers, a diminished insight in social situations and problems in verbalizing and explaining experiences have been mentioned with respect to this subject $[19,20,24,26,30]$.

Verhoeven et al. [34] suggested specific problems in affective information processing, based on findings in a case-study of an adolescent with NS and a comorbid anxiety disorder. A pilot of a larger ongoing group study confirmed an increased incidence of (type II) alexithymia in adult NS patients, while emotion recognition was intact [35].

Alexithymia, 'no words for feelings', refers to an impairment in the ability to identify and communicate emotional states [36]. Historically rooted in psychoanalytic research about the pathogenesis of psychosomatic disorders, this multidimensional concept enjoys renewed attention from a neuropsychological perspective, as evidence of a neural basis is growing [37]. Alexithymia hampers effective regulation of emotion, and constitutes a major risk factor for a range of medical and psychiatric problems, including anxiety and depression, with prevalence rates of up to $10 \%$ in the general population.

Two types of alexithymia can be distinguished. Type I is characterized by the absence of emotional experience as well as physical arousal and, consequently, by the absence of the cognition (i.e. identifying, verbalizing, analyzing) accompanying the emotion. Type II alexithymia is characterized by a selective deficit of cognition with sparing of the affective experience and normal physiological arousal [38]. In persons with type II alexithymia, which seems to be the case in NS, feelings and probably even suffering may be present, without the ability to ask for support.

Strangely, alexithymia is not associated with age, gender, educational level or intelligence [39]. It is usually measured by self-report questionnaires. Inherent to the concept, the ability to express emotions can be limited. Therefore, when measuring alexithymia, additional evaluation by proxies is recommended. 
Table 1. Psychiatric syndromes in patients with NS

\begin{tabular}{lllll}
\hline & Age (years) & Sex & IQ & Diagnosis \\
\hline Verhoeven et al. [34] & 19 & F & low & panic disorder, alexithymia \\
Verhoeven et al. [35] & 25 & M & 100 & obsessive-compulsive disorder \\
Mahendran and Aw [40] & 30 & F & $68-70$ & bipolar affective disorder \\
Krishna et al. [41] & 37 & M & 63 & schizophrenia \\
Paul et al. [42] & 4 & M & $1.5^{*}$ & autistic disorder \\
Ghaziuddin et al. [43] & 13 & M & 69 & autistic disorder \\
\hline
\end{tabular}

* Developmental age.

Psychopathology, Personality and Quality of Life

Given the prevalence of NS, remarkably few reports have been published about classical psychiatric syndromes or mental health status in NS (table 1). Just a handful of reports take note of (mostly adult) patients with psychiatric comorbidity [34, 35, 40-43].

In children, a trend towards an increased risk of behavioral problems has been noted, mainly characterized by the before-mentioned social problems, but stubbornness, restlessness, impulsivity and mood problems, like irritability or excessive happiness, have also been found $[19,20,26,30]$. Statistically significant differences in comparison with healthy controls (often siblings) or with standardization norms are hardly ever found, because of the small study groups and the large age span.

With respect to personality, research is virtually absent. Collins and Turner [12] typified the children they observed as confident, happy, talkative and reminiscent of the cocktail party manner. In the Verhoeven et al. [35] study of adult patients, friendliness, agreeableness and a tendency towards a socially desirable attitude was marked.

In the prospective study of Shaw et al. [22] with children and adults, the subject of quality of life in NS was attended to for the first time. Most patients $(n=112)$ felt their quality of life to be satisfactory or good, with only $15 \%$ reporting it was poor, due to a lack of social life or an inability to fit in. Similar results were found in a smaller Dutch study, making use of a standardized quality of life interview. Considering the fact that more than half of the patients could not function entirely autonomously, and needed some kind of educational, financial or social support, the rated quality of life is notably positive [35].

\section{Neuropsychological Findings in Adult NS}

With the purpose of assessing neuropsychological characteristics, social cognition, psychiatric symptoms and quality of life in adult patients with NS, the authors started an ongoing multidisciplinary study in 2006. During the first phase of the project, 10 patients were enrolled, whose characteristics were described in Verhoeven et al. [35]. Social cognition, in terms of emotion recognition and alexithymia, did indeed appear to be moderately impaired. As the project continues, earlier reported findings seem to be corroborated.

As can be seen in table 2, mean IQ was found to be just below average, and overall cognitive functioning appeared to be intact. In more than half of the patients, emotion identification and verbalization defects could be confirmed. A tendency was found towards social desirability and agreeableness. Patients reported average levels of life satisfaction, in contrast with the evaluation of their social functioning by proxies.

In conclusion, although no behavioral phenotype has been suggested for NS, the results of the present project show that deficiencies in social and emotional recognition and expression may be key elements. The paucity of published cases with psychiatric syndromes might be the expression of a real lower incidence or of the underreporting of psychopathology in adult NS patients.

\section{Clinical Implications}

The majority of children with NS will require special care and counseling, fitted to their developmental stage. In table 3, a detailed scheme with directives for examination and guidance of NS patients and their families is presented. Assessing developmental milestones and 
Table 2. Neuropsychological profile*

\begin{tabular}{|c|c|c|}
\hline Measurement domain & Scale & Performance \\
\hline Intelligence & $\begin{array}{l}\text { WAIS-III, total IQ } \\
\text { WAIS-III, verbal IQ } \\
\text { WAIS-III, performance IQ } \\
\text { NART-IQ }\end{array}$ & $\begin{array}{l}\text { low average } \\
\text { low average } \\
\text { low average } \\
\text { low average }\end{array}$ \\
\hline Memory & $\begin{array}{l}\text { Rey's } 15 \text { word test } \\
\text { Complex Figure Test }\end{array}$ & $\begin{array}{l}\text { average } \\
\text { average }\end{array}$ \\
\hline Attention & Stroop color-word test & average \\
\hline $\begin{array}{l}\text { Executive } \\
\text { functioning }\end{array}$ & $\begin{array}{l}\text { Tower of London test } \\
\text { Wisconsin Card Sorting Test categories } \\
\text { BADS-DEX } \\
\text { Executive Functioning Index }\end{array}$ & $\begin{array}{l}\text { average } \\
\text { RS }=5(6=\text { max. }) \\
\text { average } \\
\text { average }\end{array}$ \\
\hline Social cognition & $\begin{array}{l}\text { Emotion Recognition Task } \\
\text { Toronto Alexithymia Scale 20, total score } \\
\text { Bermond-Vorst Alexithymia Questionnaire, total score } \\
\text { BVAQ affective scale } \\
\text { BVAQ cognitive scale } \\
\text { Theory of Mind test }\end{array}$ & $\begin{array}{l}\text { average } \\
\text { average } \\
\text { low-low average } \\
\text { low average } \\
\text { low } \\
\text { low average }\end{array}$ \\
\hline Psychopathology & $\begin{array}{l}\text { SCID-I } \\
\text { SCID-II } \\
\text { Symptom Checklist psychoneuroticism } \\
\text { 10-Item Personality Inventory, agreeableness } \\
\text { 10-Item Personality Inventory, conscientiousness } \\
\text { Assertiveness scale (SIG) }\end{array}$ & $\begin{array}{l}\text { criteria met in } 4 \text { subjects } \\
\text { no classifications } \\
\text { average } \\
\text { high } \\
\text { high } \\
\text { low-low average }\end{array}$ \\
\hline Quality of life & Lancashire Quality of Life Profile, satisfaction with life & average \\
\hline
\end{tabular}

monitoring the physical and cognitive characteristics is of course important.

Since patients with NS may have an increased vulnerability to develop anxiety disorders due to the frequent co-occurence of alexithymia in adulthood, maintenance treatment with an antidepressant should be considered in such conditions [45].

One of the tasks of a neuropsychologist may be to determine school readiness and assess intellectual and other cognitive capabilities, with special attention on learning difficulties as a result of motor delay, language delay, executive dysfunctioning and inattention. A longitudinal perspective should be adopted with respect to neuropsychological evaluation because of the differences in development of the various cognitive skills. Guidance should be given while keeping in mind that NS-related problems may be underdiagnosed, and, in the case of alexithymia, it is important to help patients to give words to their experiences and possible complaints.

Given the subtlety of symptoms and their broad variation within the NS population, most reports conclude that a well-defined separate phenotype has not yet emerged. Moreover, the trend of cognitive and personal characteristics that has emerged may not be exclusive to NS, but also at least partly fits a profile that is common in mixed developmental disorders. A complex interplay of feeding difficulties with medical complications, alongside the psychosocial consequences of short stature and frequently being bullied because of dysmorphia, may add to pervasive alterations in (neuro)biological, cognitive and psychological development in NS. 
Table 3. General guidelines on examination and guidance of NS patients and their families

Developmental Examination
period

Newborns

(from birth to

1 month)
Confirm the diagnosis considering the neonatal facial features of NS, thorax deformity, possible edema, the cardiac features and cryptorchidism in the males.

Extensive cardiologic examination including echocardiography is indicated.

Perform physical examination and appropriate laboratory studies, including chromosome analysis and DNA analysis (PTPN11, SOS1, KRAS, RAF1) and discuss the results.

Document measurements, including weight, length, occipital frontal circumference and presence of hepatosplenomegaly.

Evaluate undescended testes in male patients and institute treatment if cryptorchidism is present.

\begin{tabular}{ll}
\hline $\begin{array}{l}\text { Infancy } \\
\text { (from } 1 \text { month to }\end{array}$ & $\begin{array}{l}\text { Assess growth and development in comparison to normal children } \\
\text { and to children with NS. }\end{array}$ \\
1 year) & Check motor development and arrange physiotherapy if indicated. \\
& Check for serous otitis media. \\
& Cardiologic evaluation and treatment if necessary.
\end{tabular}

Early childhood (1-5 years)

\section{Assess growth and development in comparison to normal children} and to children with NS.

Continue cardiologic evaluation.

Speech evaluation should be done at 2 years of age. Speech therapy can be of value, especially for articulation problems.

Preoperative coagulation studies including prothrombin time, partial thromboplastin time, bleeding time, and platelet count are indicated, especially if there is any clinical suspicion of a bleeding problem.

In case of severe growth retardation, growth parameters including standard GH provocative tests (arginine, glucagon, L-DOPA propranolol) and spontaneous GH secretion should be measured. In NS, partial GH deficiency can be present, although this is a rare occurrence.

Evaluate cutaneous findings, and, if prominent, refer for dermatologic examination.

Late childhood Assess and review growth and development and social adaptation.
(5-13 years)

Determine and follow up skeletal age.

Start and evaluate growth hormone therapy if indicated.

Continue cardiologic evaluation.

Determine school readiness and assess the intellectual/cognitive capabilities, with special attention for learning difficulties as a result of motor delay, language delay, executive dysfunction and inattention.

Complete eye examination and hearing evaluation should be performed in early school years.

The incidence of ophthalmologic and hearing abnormalities is high among school-aged children with NS.

Adolescence to early adulthood (13-21 years, or older)

\section{Continue to record auxological parameters.}

Determine pubertal stages according to Tanner.

Continue cardiologic evaluation.

Coagulation studies may be repeated in early adulthood. Bleeding abnormalities that are present in childhood often resolve at later age.

Continue and evaluate GH therapy (if indicated) until adult height is reached.

Repeat neuropsychological assessment, with extra attention on social cognition and social embedding.
Review the phenotype and discuss the specific findings with both parents whenever possible.

Discuss heart disease, if present, and the possibilities of treatment.

Take precautions against weight loss in the first week and hypotonia, poor feeding and failure to thrive.

Inform the parents about support groups.

Offer extensive genetic counseling to the parents.

Give advice to the parents about feeding and feeding difficulties.

Review the support available to the family.

Expect mild motor delay in most, and significant psychomotor delay only in a minority.

Discuss feeding; have feeding problems resolved? Discuss the possibility of GH therapy in very small NS children with partial GH deficiency.

Continue physiotherapy and/or speech therapy if indicated. Review easy bruising and discuss the bleeding disorder that can be present in NS. Note that there does not have to be a correlation between the bleeding problems and the results of the coagulation studies.

Evaluate behavior and possible behavioral problems, and support the parents if necessary.
Expect a delay in puberty, corresponding to the average delay in bone age of about 2 years.

Review orthodontic and speech status.

Discuss contact with other patients; this is especially valuable at this age.

Evaluate school performance.
Review school performance and choice of a profession. Discuss the diagnosis with the adolescent to be sure that the adolescent has the vocabulary and understanding of the nature of NS.

Discuss autosomal dominant inheritance in NS, the recurrence risk in children, the results of the DNA test, and the variability of expression.

Offer extensive genetic counseling.

Offer psychoeducation, help to verbalize emotions and complaints, and train social abilities to optimize adaptation. Strategies based on insights of neuropsychotherapy can usefully be applied [44].

$\mathrm{GH}=$ Growth hormone 
Advances in understanding gene-environment interaction reveal a deeply intertwined interdependency and synergy, going well beyond the outdated common sense models of both sources adding together in producing disease liability. Even single-gene disorders can present with substantial variation. Genetic expression may vary as a result of exposure to different kinds of environment, and, moreover, vary in different phases of development [4648]. Thus, the etiology of behavioral manifestations is likely to be intricate, forcing us to revise our view of the phenotypic concept.

Philosophical and methodological issues need to be addressed to enhance future research for (endo)phenotypes in NS. As suggested by Sarimski [30], studies should be based on a developmental model, incorporating genetic, biological and environmental influences, with the aim of disentangling the interplay between them and gaining insights into their effects on cognitive and behavioral maturation. Larger prospective group studies have the potential to make a meaningful contribution in this area.

\section{Disclosure Statement}

The authors have no conflicts of interest to disclose.

\section{References}

1 Lezak MD, Howieson DB, Loring DW: Neuropsychological Assessment, ed 4. New York, Oxford University Press, 2004.

2 Gottesman II, Gould TD: The endophenotype concept in psychiatry: etymology and strategy intentions. Am J Psychiatr 2003;160: 636-645.

3 Fryns JP: Progressive hydrocephalus in Noonan syndrome. Clin Dysmorphol 1997; $6: 379$.

4 Gorke W: Cerebral defects in Noonan syndrome. Klin Padiatr 1980;192:577-581.

5 Hara T, Sasaki T, Miyauchi H, Takakura K: Noonan phenotype associated with intracerebral hemorrhage and cerebral vascular anomalies: case report. Surg Neurol 1993;39: 31-36.

6 McAnena O, Padilla JR, Buckley TF: Intracranial aneurysm in association with Noonan's syndrome. Irish Med J 1984;77:140141.

7 Schon F, Bowler J, Baraitser M: Cerebral arteriovenous malformation in Noonan's syndrome. Postgrad Med J 1992;68:37-40.

8 Tanaka Y, Masuno M, Iwamoto H, Aida N, Ijiri R, Yamanaka S, Imaizumi K, Kuroki Y: Noonan syndrome and cavernous hemangioma of the brain. Am J Med Genet 1999; 82A:212-214.

9 Heye N, Dunne JW: Noonan's syndrome with hydrocephalus, hindbrain herniation, and upper cervical intracord cyst. J Neurol Neurosurg Psychiatry 1995;59:338-339.

10 Peiris A, Ball MJ: Chiari (type 1) malformation and syringomyelia in a patient with Noonan's syndrome. J Neurol Neurosurg Psychiatry 1982;45:753-754.

11 Yamashita Y, Kusaga A, Koga Y, Nagamitsu $S$, Matsuishi T: Noonan syndrome, moyamoya-like vascular changes, and antiphospholipid syndrome. Pediatric Neurol 2004; 31:364-366.
12 Collins E, Turner G: The Noonan syndrome: a review of the clinical and genetic features of 27 cases. J Pediatr 1973;83:941-950.

13 Money J, Kalus ME Jr: Noonan's syndrome: IQ and specific disabilities. Am J Dis Child 1979; 133:846-850.

14 Mendez HM, Opitz JM: Noonan syndrome: a review. Am J Med Genet 1985;21:493-506.

15 Finegan JA, Hughes HE: Very superior intelligence in a child with Noonan syndrome. Am J Med Genet 1988;31:385-389.

16 Hill P: Psychology and education in NS children. Paper, Noonan Synd Soc, Warsaw, 1992.

17 Sharland M, Burch M, McKenna WM, Patton MA: A clinical study of Noonan syndrome. Arch Dis Child 1992;67:178-183.

18 Chery M, Philippe C, Worm A, Gilgenkrantz S: The Noonan syndrome: the Nancy experience revisited. Genet Couns 1993;4:113118.

19 Van der Burgt I, Thoonen G, Roosenboom N, Assman-Hulsmans C, Gabreels F, Otten $\mathrm{B}$, et al: Patterns of cognitive functioning in school-aged children with Noonan syndrome associated with variability in phenotypic expression. J Pediatr 1999;135:707713.

20 Lee DA, Portnoy S, Hill P, Gillberg C, Patton MA: Psychological profile of children with Noonan syndrome. Dev Med Child Neurol 2005; 47:35-38.

21 Allanson JE: Noonan syndrome; in Cassidy SB, Allanson JE (eds): Management of Genetic Syndromes, ed 2. New York, WileyLiss, 2005, pp 385-399.

22 Shaw AC, Kalidas K, Crosby AH, Jeffery S, Patton MA: The natural history of Noonan syndrome: a long-term follow-up study. Arch Dis Child 2007:92:128-132.
23 Hopkins-Acos P, Bunker K: A child with Noonan syndrome. J Speech Hear Disord 1979;44:494-503.

24 Troyer AK, Joschko M: Cognitive characteristics associated with Noonan syndrome: two case reports. Child Neuropsychol 1997; 3:199-205.

25 Wilson M, Dyson A: Noonan syndrome: speech and language characteristics. J Commun Disord 1982;15:347-352.

26 Wood A, Massarano A, Super M, Harrington $\mathrm{R}$ : Behavioural aspects and psychiatric findings in Noonan's syndrome. Arch Dis Child 1995;72:153.

27 Sorter JM, Kulp MT: Are the results of the Beery-Buktenica Developmental Test of Visual-Motor Integration and its subtests related to achievement test scores? Optom Vis Sci 2003;80:758-763.

28 Horiguchi T, Takeshita K: Neuropsychological developmental change in a case with Noonan syndrome: longitudinal assessment. Brain Dev 2003;25:291-293.

29 Baddeley AD: The psychology of memory; in Baddeley AD, Wilson BA, Watts FN (eds): Handbook of Memory Disorders. Hove, Psychology Press, 2002, pp 3-15.

30 Sarimski K: Developmental and behavioural phenotype in Noonan syndrome. Genet Couns 2000;11:383-390.

31 Van Rijn S: Exploring Social Cognitive Pathways to Psychopathology; thesis, Utrecht University, 2007.

32 Adolphs R: What is special about social cognition?; in Cacioppo JT, Visser PS, Pickett CL (eds): Social Neuroscience: People Thinking about Thinking People. Cambridge, MIT, 2006, pp 269-285.

33 Adolphs R: The neurobiology of social $\operatorname{cog}$ nition. Curr Opin Neurobiol 2001;11:231239. 
34 Verhoeven WMA, Hendrikx JLM, Doorakkers MC, Egger JIM, Van der Burgt I, Tuinier S: Alexithymia in Noonan syndrome. Genet Couns 2004;15:47-52.

35 Verhoeven WMA, Wingbermühle E, Egger J, Van der Burgt I, Tuinier S: Noonan syndrome: psychological and psychiatric aspects. Am J Med Genet 2007;146A:191196.

36 Sifneos PE: The prevalence of 'alexithymic' characteristics in psychosomatic patients. Psychother Psychosom 1973;22:255-262.

37 Aleman A: Feelings you can't imagine: towards a cognitive neuroscience of alexithymia. Trends Cogn Sci 2005;9:553-555.

38 Vorst HCM, Bermond B: Validity and reliability of the BVAQ. Pers Individ Dif 2001; $30: 413-434$.
39 Parker JD, Taylor GJ, Bagby RM: The alexithymia construct: relationship with sociodemographic variables and intelligence. Compr Psychiatry 1989;30:434-441.

40 Mahendran R, Aw SC: Noonan's syndrome with mental retardation presenting with an affective disorder: case report. Singapore Med J 1989;30:306-307.

41 Krishna NR, Abrams R, Taylor M, Behar D: Schizophrenia in a $46, \mathrm{XY}$ male with the Noonan syndrome. Br J Psychiatry 1997;130: 570-572.

42 Paul R, Cohen DJ, Volkmar FR: Autistic behaviors in a boy with Noonan syndrome. J Autism Dev Disord 1983;13:433-434.

43 Ghaziuddin M, Bolyard B, Alessi N: Autistic disorder in Noonan syndrome. J Intellect Disabil Res 1994;38:67-72.
44 Grawe K: How the Neurosciences Inform Effective Psychotherapy. Mahwah, Lawrence Erlbaum Associates, 2006.

45 Verhoeven WMA, Tuinier S: Serotonin uptake inhibitors in patients with intellectual disabilities; in Shirley AC (ed): Trends in Serotonin Uptake Inhibitors Research. New York, Nova Science, 2005, pp 152-172.

46 Kendler KS, Greenspan RJ: The nature of genetic influences on behavior: lessons from 'simpler' organisms. Am J Psychiatry 2006; 163:1683-1694.

47 Moore DS: The Dependent Gene: The Fallacy of 'Nature vs. Nurture'. New York, Henry Holt, 2003.

48 Rutter M: Gene and Behavior: Nature/Nurture Interplay Explained. Oxford, Blackwell Publishing, 2006. 